\title{
Philippe Levillain, Gilles Ferragu (éd), Albert de Mun, Hubert Lyautey. Correspondance, 1891-1914
}

Paris, Société de l'Histoire de France, 2011. 284 p.

\section{Paul Airiau}

\section{(2) OpenEdition}

Édition électronique

URL : http://journals.openedition.org/assr/24030

DOI : $10.4000 /$ assr. 24030

ISSN : $1777-5825$

Éditeur

Éditions de l'EHESS

Édition imprimée

Date de publication : 30 décembre 2012

Pagination : 227

ISSN : 0335-5985

Référence électronique

Paul Airiau, «Philippe Levillain, Gilles Ferragu (éd), Albert de Mun, Hubert Lyautey. Correspondance, 1891-1914 ", Archives de sciences sociales des religions [En ligne], 160 | octobre-décembre 2012, mis en ligne le 18 mars 2013, consulté le 21 septembre 2020. URL : http://journals.openedition.org/assr/ 24030 ; DOI : https://doi.org/10.4000/assr.24030

Ce document a été généré automatiquement le 21 septembre 2020.

(c) Archives de sciences sociales des religions 


\section{Philippe Levillain, Gilles Ferragu (éd), Albert de Mun, Hubert} Lyautey. Correspondance, 1891-1914 Paris, Société de l'Histoire de France, 2011. 284 p.

\section{Paul Airiau}

\section{RÉFÉRENCE}

Philippe Levillain, Gilles Ferragu (éd), Albert de Mun, Hubert Lyautey. Correspondance, 1891-1914, Paris, Société de l'Histoire de France, 2011. 284 p. 
1 Le XIX ${ }^{e}$ siècle fut un siècle épistolaire, la chose est connue. Et il reste toujours des correspondances à éditer, pour permettre, notamment, aux historiens de travailler. C'est ce que font Philippe Levillain et Gilles Ferragu avec la correspondance échangée entre un catholique intransigeant et monarchiste, Albert de Mun, et un officier catholique libéral et colonial, Hubert Lyautey.

2 L'introduction permet d'entrer dans ces lettres en soulignant la proximité puis la divergence religieuse qui exista entre ces deux officiers séparés par une demigénération, puis enfin leur rapprochement autour des questions militaires, c'est-à-dire de la grandeur de la France. Beaucoup peut être tiré de ces lettres, notamment grâce à l'index et aux précises notes infrapaginales présentant

\section{ALBERT DE MUN HUBERT LYAUTEX CORRESPONDANCE $1891-594$}

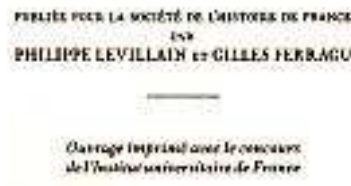

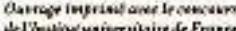

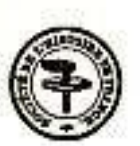

mars

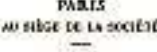

$\overline{x i 1}$

as personnages et événements: l'influence prêtée à l'écrit journalistique pour orienter les idées et les décisions politiques, le fonctionnement parlementaire, les réalités coloniales au Maroc, la caisse de résonance sociale et donc l'enjeu qu'est l'Académie française, et bien plus encore - tout ce qui donne une dimension profondément exotique à ces échanges, tant le monde a changé.

Du point de vue religieux, on retiendra l'importance de la matrice catholique dans ce qu'est l'engagement social à la fin du XIX ${ }^{e}$ siècle, quel que soit le sens donné à cet engagement, et quel que soit le catholicisme à la source de ce même engagement, l'objectif commun étant la réforme de la France, au service de sa grandeur. On relèvera aussi, à la suite de l'introduction, l'importance de la fracture entre libéraux et intransigeants à partir de la fin des années 1870, qui aboutit, en partie, à une autoexclusion des libéraux, qu'ils perçoivent comme une expulsion. Mais est-on ici encore dans l'exotisme? 